\title{
STUDY OF OLIGOCLONAL BANDS RESTRICTED TO THE CEREBROSPINAL FLUID IN MULTIPLE SCLEROSIS PATIENTS IN THE CITY OF SÃO PAULO
}

\author{
Paulo Diniz da Gama ${ }^{1,2}$, Luís dos Ramos Machado3, José Antonio Livramento3, \\ Hélio Rodrigues Gomes ${ }^{4}$, Tarso Adoni ${ }^{2,4}$, Angelina Maria Martins Lino ${ }^{3}$, Paulo Euripedes Marchiori ${ }^{3}$, \\ Rogério de Rizo Morales ${ }^{4}$, Marco Aurélio Lana-Peixoto ${ }^{5}$, Dagoberto Callegaro 6
}

\begin{abstract}
The frequency of oligoclonal bands (OCB) restricted to the cerebrospinal fluid (CSF) from patients with multiple sclerosis (MS) varies widely in different populations. The objective of this study was to determine the frequency of these OCB in a group of MS patients in the city of São Paulo. Techniques used to detect OCB consisted of isoelectric focusing followed by immunoblotting. Oligoclonal bands were found in 49 (54.4\%) out of 90 patients with clinically definite MS; in (31.2\%) of the 16 patients with clinically isolated syndrome; in $7(17.9 \%)$ of 39 patients with inflammatory disorders of the central nervous system (IDCNS), and in none of the individuals with no neurological condition (control group). The specificity of the method was $100 \%$ when compared to the control group and $82.1 \%$ when compared to the IDCNS group. These results suggest that the frequency of CSF OCB is much lower in Brazilian MS patients from São Paulo city than that reported in MS series from Caucasian populations.
\end{abstract}

KEY WORDS: multiple sclerosis, cerebrospinal fluid, oligoclonal bands, Brazilian population.

\begin{abstract}
Estudo de bandas oligoclonais restritas ao líquido cefalorraquidiano em pacientes com esclerose múltipla na cidade de São Paulo

Resumo - A frequência da detecção de bandas oligoclonais (BOC) restritas ao líquido cerebrorraquidiano (LCR) em pacientes com esclerose múltipla (EM) varia amplamente em diferentes populações. O objetivo deste estudo foi determinar a frequência destas $\mathrm{BOC}$ em pacientes com EM em amostra de população da cidade de São Paulo. A técnica utilizada para a detecção das BOC foi a focalização isoelétrica, seguida do immunoblotting. BOC foram detectadas: em $49(54,4 \%)$ de 90 pacientes com EM clinicamente definida; em 5 $(31,2 \%)$ de 16 pacientes com sindrome clínica isolada; em $7(17,9 \%)$ de 30 pacientes com doenças inflamatórias do sistema nervoso central (DISNC); e em nenhum indivíduo sem doença neurológica. A especificidade do método foi $100 \%$ quando comparada ao grupo controle e $82,1 \%$ quando comparada ao grupo de DISNC. Estes resultados sugerem que a freqüência de BOC no LCR é mais baixa em pacientes da cidade de São Paulo portadores de EM do que aquelas descritas em populações caucasianas.
\end{abstract}

PALAVRAS-CHAVE: esclerose múltipla, líquido cefalorraquidiano, bandas oligoclonais, população brasileira.

Multiple sclerosis (MS) is an inflammatory central nervous system (CNS) disorder, increasingly diagnosed in tropical countries. The anatomical substrate is the finding of inflammation, demyelination, axonal degeneration and gliosis. Although its etiology still remains a mystery, autoim- mune mechanisms must play an essential role in its pathogenesis ${ }^{1-4}$. MS diagnosis is still largely based upon clinical evidences. However, magnetic resonance imaging (MRI), and cerebrospinal fluid (CSF) analysis are important tools for recognizing the topography, extent, phase of the le-

\footnotetext{
Department of Neurology and Neurosurgery of the Faculty of Medicine of University of São Paulo (USP), São Paulo SP, Brazil: 'Assistant Professor, Pontifical Catholic University of São Paulo, São Paulo SP, Brazil; ${ }^{2}$ Post-Graduate Student of Neurology, USP; ${ }^{3}$ Associate Professor of Neurology, USP; ${ }^{4}$ Neurologist, USP; ${ }^{5}$ Associate Professor of Neurology and Ophthalmology, Federal University of Minas Gerais, Belo Horizonte MG, Brazil; ${ }^{6}$ Associate Professor and Responsible for the Demyelinating Diseases Reference Center of the Clinical Hospital of the Faculty of Medicine University of São Paulo and the Brazilian Committee for Treatment and Research in Multiple Sclerosis (BCTRIMS), Belo Horizonte MG, Brazil.
} 
sions, characterization of the local immune response and differential diagnosis with other neurological diseases ${ }^{2,5,6}$.

CNS inflammation in MS can be estimated by intrathecal production of immunoglobulins (IgG). This production can be assessed by the finding of IgG bands in the CSF system without a clear recognition of the same bands in the serum, i.e. CSF oligoclonal bands $(\mathrm{OCB})^{1,6}$.

Different MS populations living in different countries appear to have different prevalence rates of CSF OCB. The prevalence rate is as high as 90 to $95 \%$ in Scandinavia ${ }^{7-9}$, and as low as 30 to $60 \%$ in China, Japan, Lebanon and In$\mathrm{dia}^{10-13}$. We describe the frequency of OCB in the CSF of a group of MS patients in the city of São Paulo, Brazil.

\section{METHOD}

The cohort comprised 164 patients seen at the Demyelinating Disorders Outpatient Clinics of the University of São Paulo Medical School. All patients or their legal guardians signed the informed consent agreement. The study was authorized by the Research Ethics Committee of the institution.

The patients' history, physical examination and analysis of the MRI were all done at the first visit, and then re-evaluated by a second researcher. Both researchers were neurologists with expertise in MS diagnosis. Diagnosis was based upon the international criteria of McDonald, revised in $2005^{14}$.

Serological tests (hemogram; erythrocyte sedimentation rate; urea and creatinine; transaminases; total and fractionated bilirubin; glycemia; calcium; free thyroxin; thyroid-stimulating hormone; C-reactive protein; anti-nuclear factor; latex test, fractions of the complement, anticardiolipin antibodies; cyanocobalamin and folate dosage; immunological reactions for syphilis, hepatitis B and C, HIV and HTLV) were requested to exclude diseases that could have differential diagnosis with MS.

No OCB investigation was made previously in CSF from these patients. So, the results of the CSF analysis were not used to establish the diagnosis or to include patients in this study.

We divided subjects into four different groups. Group 1 comprised 90 patients with clinically-definite multiple sclerosis (CDMS) according to McDonald's criteria ${ }^{14}: 61$ with relapsing remitting form (RR); 11 with secondary-progressive form (SP); 16 with primary-progressive form (PP); 2 with progressive relapsing form (PR). Group 2 comprised 16 individuals who presented a clinically isolated syndrome (CIS) indicative of a CNS first demyelinating event. Group 3 comprised 39 patients with a variety of chronic inflammatory disorders of the CNS. Group 4 comprised 19 subjects with neither neurological complaints nor infectious conditions, whose CSF sample was collected during anesthetic procedure for minor surgery.

Blood serum and CSF analysis were carried out simultaneously. The CSF analysis included the classical routine tests (cytomorphological profile; determination of total protein content; dosage of glucose) and immunological reactions for the infectious diseases more frequently observed in tropical countries ${ }^{2,3,6}$.

The technique used to assess the OCB was isoelectric fo- cusing (IF) in polyacrylamide gel (ETC - Elektrophorese - Technok Bahnhofstr). Each paired sample of CSF and blood serum was submitted to IF (CWP-400 Isolab Inc) always with a positive control. If was transferred to a nitrocellulose membrane (Bio Agency), followed by immunoblotting using a primary antibody (Goat-anti-human IgG, Sigma) and a polyclonal rabbit anti-goat immunoglobulin (Dako Cytomation) as a secondary antibody. Subsequently, the reaction was developed using 3-amino-9-ethylcarbazole (Sigma). OCB were considered recognized when two or more bands were found in the CSF, but absent in the serum. All IF were examined by two specialists who were not aware to which group the samples belonged. In a case of discrepant or dubious interpretation of results, the sample was processed again.

Quantitative intrathecal immunoproduction of IgG was carried out in parallel. Concentrations of IgG and albumin both in the serum and CSF were measured by nephelometry. This allowed to determine: (1) the CSF/serum ratio for IgG or IgG quotient $\left(\lg G_{Q}\right)$ and the CSF/serum ratio for albumin or albumin quocient $\left(A_{Q}\right)$; (2) IgG index (the ratio between $\lg G_{Q}$ and $A_{Q}$ ); (3) Reiber and Felgenhauer nomogram.

$A_{Q}$ values were considered increased for values of $6,5 \times 10^{-3}$ or higher. $A_{Q}$ over $8 \times 10^{-3}$ in patients with more than 40 years are considered normal. IgG index was considered increased for values $\geq 0.8$.

\section{RESULTS}

Table 1 shows the demographic characteristics of the patients.

Out of the 90 patients with CDMS, 49 (54.4\%) presented OCB restricted to the CSF. These OCB were detected in 21 out of 41 CDMS patients (51.2\%) who were in use of immunomodulatory agents. Fig 1 shows the frequencies of positive CSF OCB according to the clinical course of MS (27 RR, 6 SP, 14 PP and 2 PR).

The sensitivity of OCB in patients with MS in our study was $54.4 \%$. The specificity was $100 \%$ when patients without neurological disease were used as controls; $82.1 \%$ when patients with inflammatory diseases of the CNS were used as the control. These data, together with the accuracy and the positive and negative predictor values are shown in Table 2.

As shown in Fig 1, OCB were more frequent in progressive forms (PP, SP and PR) than in RR form of MS ( $p=0.009)$.

In the group of patients with CIS, positive CSF OCB were found in $5(31.2 \%)$ out of 16 patients. There was no statistical difference between the frequency of OCB in patients with CIS when compared to patients with RR form of $\mathrm{MS}$ ( $\mathrm{p}=0.35$ ) (Fig 1).

OCB were found in $7(17.9 \%)$ out of 39 patients with inflammatory diseases of the CNS. This frequency is much smaller than that observed for the pool of MS patients $(p=0.00002)$ and for the subgroup of patients with RR form of MS $(p=0.001)$.

No OCB were found in patients from the control group. 
Table 1. Demographic characteristics of the studied population.

\begin{tabular}{lccccc}
\hline & & & Gender & \multicolumn{2}{c}{ Ethnical origin } \\
\cline { 5 - 6 } Groups & $\mathrm{N}$ & Age media & F/M & European & African \\
\hline MS & 90 & $35.6 \pm 12.1$ & $2.9 / 1$ & $72 \%$ & $18 \%$ \\
CIS & 16 & $25.4 \pm 8.2$ & $2.2 / 1$ & $81 \%$ & $19 \%$ \\
ID & 39 & $31.5 \pm 18.4$ & $2.3 / 1$ & $54 \%$ & $46 \%$ \\
NNC & 19 & $39.2 \pm 16.2$ & $2.2 / 1$ & $63 \%$ & $37 \%$ \\
\hline
\end{tabular}

N: number; MS: multiple sclerosis; CIS: clinical isolated syndrome; ID: inflammatory disease of the central nervous system; NNC: no neurological complain.

Table 2. Indicators of significance in the detection of OCB for the diagnosis of multiple sclerosis, using the isoelectric focusing technique followed by immunoblotting.

\begin{tabular}{lcc}
\hline OCB in multiple sclerosis & $\begin{array}{c}\text { Control } \\
\text { group (\%) }\end{array}$ & $\begin{array}{c}\text { ID } \\
\text { group (\%) }\end{array}$ \\
\hline Sensitivity & 54.4 & 54.4 \\
Specificity & 100 & 82.1 \\
Accuracy & 77.2 & 68.2 \\
Positive predictor value & 100 & 75.2 \\
Negative predictor value & 68.6 & 64.2 \\
\hline
\end{tabular}

OCB: oligoclonal bands; control group: patients submitted to spinal tap for anesthesia; ID group: inflammatory diseases of the central nervous system.

Table 3. Frequency of restricted oligoclonal bands to the cerebrospinal fluid in patients with inflammatory diseases of the central nervous system.

\begin{tabular}{lccc}
\hline & \multicolumn{3}{c}{ OCB +} \\
\cline { 2 - 4 } & $\mathrm{n}$ & $\mathrm{n}$ & $\%$ \\
\hline Relapsing optic neuritis & 2 & 2 & 100 \\
HTLV myelopathy & 2 & 1 & 50 \\
Schistosomiasis & 2 & 1 & 50 \\
CNS vasculitis & 15 & 3 & 20 \\
Neuromyelitis optica & 6 & 0 & 0 \\
Relapsing myelitis & 4 & 0 & 0 \\
ADEM & 3 & 0 & 0 \\
Hepatitis B and C & 3 & 0 & 0 \\
Syphilis & 1 & 0 & 0 \\
Viral optic neuritis & 1 & 0 & 0 \\
\hline
\end{tabular}

OCB+: presence of oligoclonal bands by isoelectric focusing and immunoblotting); $\mathrm{n}$ : number of patients; CNS: central nervous system; ADEM: acute disseminated encephalomyelitis.

Table 3 shows the frequency of positive OCB in the CSF of patients with a variety of inflammatory diseases of the CNS. The frequencies of OCB in the CSF of MS patients in different populations worldwide are shown in Table 4.

The IgG index was abnormal in 42 of the 90 patients with CDMS (46.6\%), with a median of 0.8 , media of 1.02

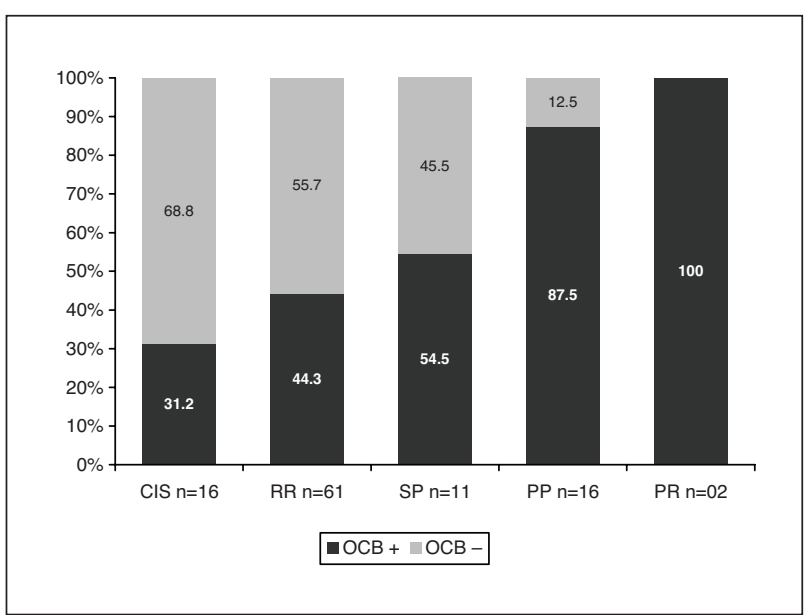

Fig 1. Correlation between the clinical forms of multiple sclerosis and analysis of cerebrospinal fluid. CIS: clinically isolated syndrome; RR: relapsing remitting; SP: secondary-progressive; PP: primary-progressive; PR: progressive relapsing; OCB: oligoclonal bands by isoelectric focusing and immunoblotting. No-association test for CIS and RR: $p=0.35$ and $R R$ to progressive forms: $p=0.009$.

(SD 0.67). Sensitivity of the IgG index for the diagnosis of MS was $46.6 \%$; specificity was $94.8 \%$ when patients without neurological disease were used as controls, and $64.2 \%$ when patients with inflammatory diseases of the CNS were used as controls.

There was concordance between the presence of OCB and increased IgG index in 37 patients with MS (41.1\%). Detection of $O C B$ and/or increased values of IgG index may allow to characterize the CSF immunoproduction of IgG in 57 out of 90 patients $(63.3 \%)$.

In the group of patients with inflammatory diseases of the CNS, increased IgG index was found in 14 of 39 patients (35.8\%).

In the control group, one of the 19 patients presented a slight increase in IgG index (5.2\%).

Reiber and Felgenhauer nomogram for quantitative evaluation of immunoproduction is shown in Fig 2. The comparative study of qualitative (OCB) and quantitative IgG immunoproduction (IgG index) is shown in Fig 3.

The median cell count in the CSF was $5 \mathrm{cell} / \mathrm{mm}^{3}$. 


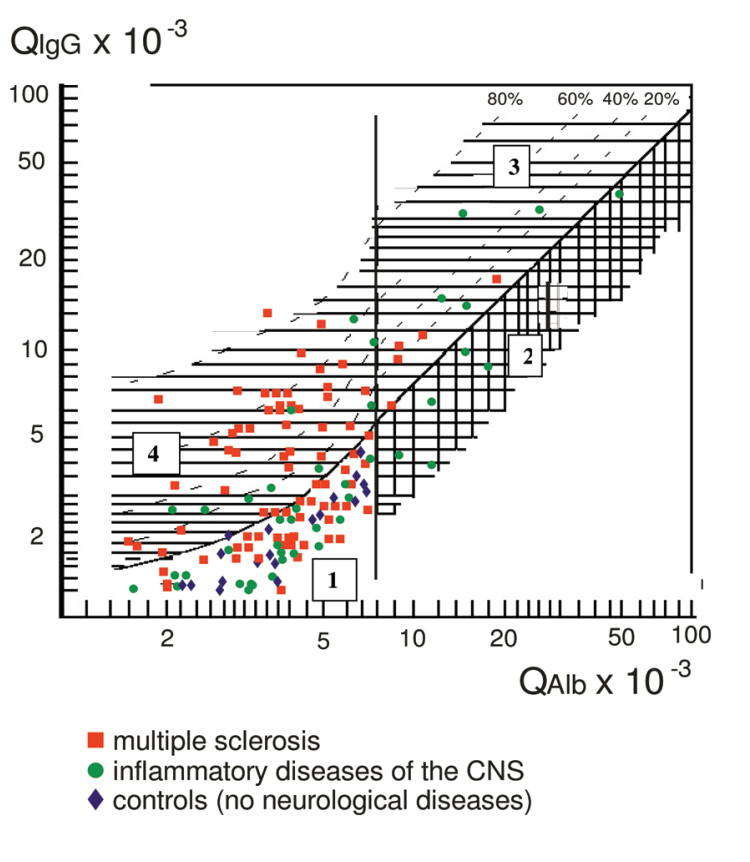

Fig 2. Quotient of immunoglobulin plotted against the quotient of albumin for the three groups of patients. QIgG: IgG quocient; QAlb: albumin quocient; region 1: normal; region 2: blood-brain barrier breakdown; region 3: blood-brain barrier breakdown associated with local synthesis; region 4: local synthesis.

Pleocytosis up to 30 cells $/ \mathrm{mm}^{3}$ (mononuclear cells) was seen in $51.7 \%$ of the patients. In $98.1 \%$ of the patients with MS, the total protein content (mean: $31.3 \mathrm{mg} / \mathrm{dl}, \mathrm{SD}: 7.2$, median: $29 \mathrm{mg} / \mathrm{dL}$ ) was below $72 \mathrm{mg} / \mathrm{dl}$ and the total cell count was below 30 cells $/ \mathrm{mm}^{3}$. Glucose concentration was normal in all patients. $Q_{A}$ was high in $14.1 \%$, suggesting some degree of dysfunction of the blood-CSF barrier.

All immunological tests showed either normal results or slight alterations without clinical significance.

\section{DISCUSSION}

Our study showed that $54.4 \%$ of the patients with CDMS had OCB restricted to the CSF. The sensitivity of this finding was $100 \%$ when compared to patients without neurological diseases, and $82.1 \%$ when compared to patients with inflammatory diseases of the CNS.

The frequency of $O C B$ found in this study is low in comparison with both the prevalence observed in European and North-America MS patients and other previous Brazilian studies which found a frequency of $85 \%{ }^{17}$ and $91 \%{ }^{18}$. However, this low rate is similar to that observed in other regions of the world (Table 4).

Three main hypotheses may be postulated to explain the lower results for $O C B$ detection in our study: (a) there was a bias in clinical evaluation of the patients included; (b) there were problems in methodology for CSF analy-

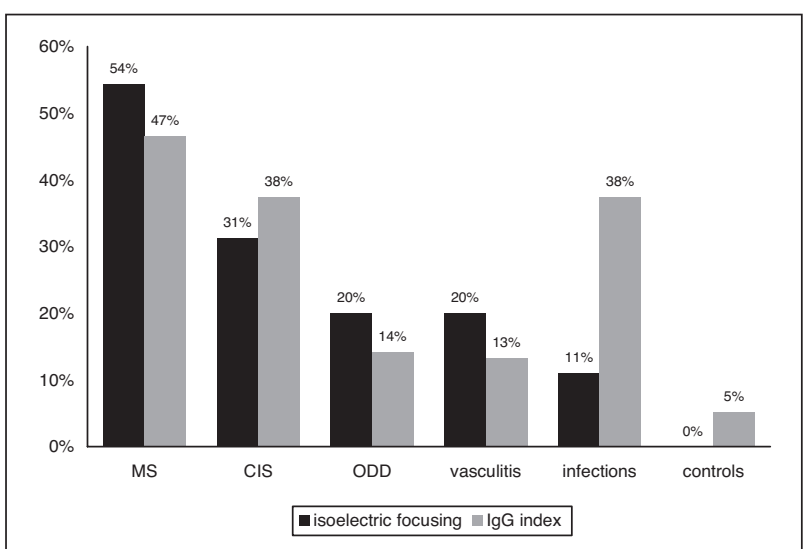

Fig 3. Comparison of the frequency of positive oligoclonal bands and IgG index $\geq 0.8$ in the cerebrospinal fluid of patients with different central nervous system disorders and controls. MS: multiple sclerosis; CIS: clinically isolated syndrome; ODD: other demyelinating disease, include neuromyelitis optica, acute disseminated encephalomyelitis, relapsing myelitis and relapsing optic neuritis; controls: patients submitted to spinal tap for anesthesia.

sis of these patients; (c) OCB does occur in a smaller percentage in São Paulo city by unknown reasons.

As for the first hypothesis, a special and intensive care was taken to include only patients with MS clinical definite. The inclusion criteria strictly followed recommendations for MS diagnosis, widely discussed in the international panel of McDonald revised in $2005^{14}$. These patients were carefully and independently examined by two experienced neurologists, with expertise in MS diagnosis and treatment. Therefore, this hypothesis is highly unlikely to explain this finding.

As for the second hypothesis, some considerations must be made: (1) the results of CSF analysis were not used as an inclusion criteria; (2) our study was carried out in an academic reference laboratory with a very experienced research staff in CSF analysis, mainly in electrophorectic methods. The CSF sample was processed using high standards according to CSF Analysis Consensus of Freedman MS et al. ${ }^{6}$. This included the use of the most up-to-date internationally accepted technology and strict adherence to the criteria of reproducibility ensuring high levels of fidelity of the results; (3) the IF method followed by immunoblotting used in our patients is the most sensitive and suitable technique for detecting $\mathrm{OCB}$ when MS is suspected ${ }^{6}$. Nevertheless, the use of this technique is not a universal practice: according to the College of American Pathologists Survey ${ }^{16}$, only $10 \%$ of the 235 laboratories in the USA that conduct CSF analysis use this technique to detect OCB. This clearly shows that, unlike our group, in practice, the most suitable method for investigating $O C B$ has been underutilized in many research centers, even in the most developed countries; (4) the analysis of paired CSF and serum electrophoresis was made by two skilled 
Table 4. Frequency of oligoclonal bands restricted to the cerebrospinal fluid of patients with multiple sclerosis in different countries.

\begin{tabular}{|c|c|c|c|c|c|}
\hline \multirow[b]{2}{*}{ Country } & \multirow[b]{2}{*}{ Method } & \multicolumn{3}{|c|}{$\% \mathrm{OCB}+$} & \multirow[b]{2}{*}{ References } \\
\hline & & MS & ID & Control & \\
\hline Norway & IEF IF & $100 \%$ & & $9 \%$ & Lunding J et al. $2000^{9}$ \\
\hline Slovenia & IEF IF & $95 \%$ & & & Rot et al. $2008^{8}$ \\
\hline Norway & IEF IB & $93 \%$ & $67 \%$ & $4 \%$ & Mygland A et al. $2007^{7}$ \\
\hline USA & IEF IB & $90 \%$ & & $6 \%$ & Fortini AS et al. $2003^{20}$ \\
\hline Canada & IEF IB & $89 \%$ & & & Siritho S et al. $2009^{26}$ \\
\hline Italy & IEF & $89 \%$ & & & Annunziata P et al. $2006^{27}$ \\
\hline Spain & IEF IB & $87 \%$ & $52 \%$ & $17 \%$ & Falip M et al. $2001^{15}$ \\
\hline France & $\mathrm{IEF}$ & $85 \%$ & $21 \%$ & $8 \%$ & Bourahoui A et al. $2004^{28}$ \\
\hline Portugal & IEF IF & $82 \%$ & $40 \%$ & $3 \%$ & Sá MJ et al. $2005^{19}$ \\
\hline Czech Rep. & IEF IB & $81 \%$ & & $7 \%$ & Bednarova et al. $2005^{29}$ \\
\hline Holland & IEF IF & $76 \%$ & & & Koch $M$ et al. $2007^{30}$ \\
\hline France & IEF IF & $76 \%$ & & $7 \%$ & Fromont A et al. $2005^{21}$ \\
\hline China & IEF SS & $63 \%$ & $47 \%$ & $4 \%$ & Li B et al. $2007^{10}$ \\
\hline Japan & IEF IF SS & $56 \%$ & & & Fukazawa et al. 1998 ${ }^{11}$ \\
\hline China & NR & $40 \%$ & & & Lau KK et al. $2002^{23}$ \\
\hline Lebanon & NR & $40 \%$ & & & Yamout B et al. $2008^{12}$ \\
\hline Japan & IEF & $33 \%$ & & & Tanaka K et al. $2005^{24}$ \\
\hline India & NR & $30 \%$ & & & Syal P et al. $1999^{13}$ \\
\hline Taiwan & $\mathrm{IEF}$ & $7 \%$ & $0 \%$ & & Chang KH et al. $2006^{31}$ \\
\hline Brazil & IEF IB & $54 \%$ & $17 \%$ & $0 \%$ & Present study \\
\hline
\end{tabular}

ID: inflammatory diseases of the central nervous system; IEF: isoelectric focusing; IB: immunoblotting; IF: immunofixation; SS: silver staining; NR: no reference.

researchers unaware of the diagnosis of the patients. So, the low frequency of OCB founded in this study may not be ascribed to problems in CSF analysis.

Apart from the relatively low sensitivity, the detection of OCB seemed to have a low specificity, mainly when a blind method of analysis was used ${ }^{7,8}$. OCB have been described in other inflammatory diseases, their frequency of detection ranging from 25 to $80 \%$, 5,719 , as well as in noninflammatory diseases of the CNS (in up to $17 \%$ of patients $\left.{ }^{15}\right)$. However, there is no consensus about this low specificity of OCB in MS.,20,21.

In the MS group, OCB were observed more frequently in progressive forms than in RR form. This may be explained by the continuous course of the disease and a consequent more effective exposition to immunological mechanisms in those forms of MS.

On the other hand, the frequency of OCB observed in patients with CIS is similar to that observed in patients with RR form of MS. This observation may give rise to two comments: (a) CIS is a true form of MS; (b) our clinical appraisal of patients included in this study was fully satisfactory.
The quantitative determination of immunoproduction of IgG must be made in addition to OCB search. This complementary method seems to improve the sensitivity of CSF diagnosis in MS, since $8.9 \%$ of patients with definite MS diagnosis presented increased IgG index without OCB in CSF. However, it remains to be explained why this difference occurs and what is the meaning of this finding.

The relatively low frequency of increased $A_{Q}$ observed in CSF samples studied suggests that our MS patients do not often have impairment of the blood-brain-barrier (BBB) function.

The Reiber and Felgenhauer nomogram is a very interesting quantitative method to evaluate CSF intrathecal IgG production. It permits to recognize: (1) the patients in which no IgG immunoproduction nor BBB breakdown is happening (region 1 of Fig 2); (2) the occurrence of BBB breakdown, more usually seen in inflammatory diseases other than MS (region 2 of Fig 2); (3) the association of immunoproduction and BBB breakdown as it is shown in the region 3 of the Fig 2. This characteristic may be important in patients with MS, since it is probably the only complementary diagnostic method that allows recogni- 
tion of the acute phase phenomena (BBB breakdown) taking place over an older chronic immunoproducing process. This information may be helpful for distinction when images seen at MRI may correspond to acute lesions or only to cicatricial demyelination; (4) the graphic representation of samples from patients with IgG immunoproduction is displayed in a similar way to that of the Link's IgG index analysis (region 4 of Fig 2).

Although CSF analysis in MS aims to characterize the local immune response in the CNS, a number of other features may differentiate MS from other diseases of the CNS, such as: (1) in MS, there is usually a high number of OCB; (2) in MS, the simultaneous presence of OCB in CSF and in the blood serum is uncommon, even if a high number of bands have been identified in the CSF; (3) there usually is a normal number of cell count or a slight pleocytosis, usually below 30 cells $/ \mathrm{mm}^{3}$, with an absolute predominance of lymphomononuclear cells; (4) the total protein content is usually normal or slightly above normal, generally below $70 \mathrm{mg} / \mathrm{dL}$; (5) the concentration of glucose should be within reference limits ${ }^{2-4,20}$.

These data show the importance of the CSF analysis in all MS patients, mainly in those with initial clinical symptoms of demyelinating diseases. The detection of this CSF profile may be helpful to suggest the occurrence of an inflammatory process in the CNS, especially in patients whose clinical and imaging abnormalities are not clearcut, thus providing the possibility of early diagnosis and treatment ${ }^{8,25}$. This is more important in progressive forms of MS, mainly in the primary progressive form.

In conclusion, the expected results for the frequency of OCB in MS patients in Brazil cannot be estimated by simple extrapolation from the data obtained in European or North American populations. Possibly, variations in the clinical presentation and genetic susceptibility may determine the occurrence of significant variations $\mathbf{s}^{11,22-24}$.

\section{REFERENCES}

1. Reiber H. Cerebrospinal fluid: physiology, analysis and interpretation of protein patterns for diagnosis of neurological diseases. Mult Scler 1998;4:99-107.

2. Link H, Huang Y-M. Oligoclonal band in multiple sclerosis cerebrospinal fluid: an update on methodology and clinical usefulness. J Neuroimmunol 2006;180:17-28.

3. Zettl UK, Tumani H. Multiple sclerosis \& cerebrospinal fluid. Navarra Spain: Blackwell Publishing Ltd, 2005: 1-116.

4. Correale J. Oligoclonal bands and antibody responses in multiple sclerosis. J Neurol 2002;249:375-389.

5. Reske D, Petereit H-F, Heis W-D. Difficulties in the differentiation of chronic inflammatory diseases of the central nervous system: value of cerebrospinal fluid analysis and immunological abnormalities in the diagnosis. Acta Neurol Scand 2005;112:207-213.

6. Freedman MS, Thompson EJ, Deisenhammer F, et al. Recommended standard of cerebrospinal fluid analysis in the diagnosis of multiple sclerosis: a consensus statement. Arch Neurol 2005;62:865-870.

7. Mygland A, Trydal T, Vinje BU, Vedeler C. Isoelectric focusing is superior to immunofixation eletrophoresis in diagnosing CNS inflammation. Acta Neurol Scan 2007;115:122-125.
8. Rot U, Ledinek AH, Jazbec SS. Clinical, magnetic resonance imaging, cerebrospinal fluid and electrophysiological characteristics of the earliest multiple sclerosis.Clin Neurol Neurosurg 2008;110:233-238.

9. Lunding J, Midgard R, Vedeler CA. Oligoclonal bands in cerebrospinal fluid: a comparative study of isoelectric focusing, agarose gel electrophoresis and IgG index. Acta Neurol Scand 2000;102:322-325.

10. Li B, Dong H, Zhang J, Song X, Guo L. Cerebrospinal fluid IgG profiles and oligoclonal bands in Chinese patients with multiple sclerosis. Acta Neurol Scand 2007;115:319-324.

11. Fukazawa T, Kikuchi S, Sasaki H, et al. The significance of oligoclonal bands in multiple sclerosis in Japan: relevance of immunogenetic backgrounds. J Neurolo Sci 1998;158:209-214.

12. Yamout B, Barada W, Tohme RA, Mehio-Sibai A, Khalifeh R, El-Hajj T. Clinical characteristics of multiple sclerosis in Lebanon. J Neurol Sci 2008;270:88-93

13. Syal P, Prabhakar S, Thussu A, Sehgal S, Khandelwal N. Clinical profile of multiple sclerosis in north-west India. Neurol India 1999;47:12-17.

14. Polman D, Reingold SC, Edan G, et al. Diagnostic criteria for multiple sclerosis: 2005 revisions to the "McDonald Criteria". Ann Neurol 2005; 58:840-846

15. Falip M, Tintoré M, Jardi R, Duran I, Link H, Montalbán S. Utilida clínica de las bandas oligoclonales. Rev Neurol 2001;32:1120-1124.

16. Keren DF. Optimizing detection of oligoclonal band in cerebrospinal fluid by use of isoelectric focusing with IgG immunoblotting. Am J Clin Pathol 2003;120:649-651.

17. Puccioni-Sohler M, Lavrado FP, Bastos RRG, Brandão CO, Papaiz-Alvarenga R. Esclerose múltipla: correlação clínico-laboratorial. Arq Neuropsiquiatr 2001;59:89-91.

18. Brandão $\mathrm{CO}$, Ruocco HH, Farias AS, et al. Cytokines and intrathecal IgG synthesis in multiple sclerosis patients during clinical remission. Arq Neuropsiquiatr 2005;63:914-919.

19. Sá MJ, Sequeira L, Rio ME, Thompson EJ. Oligoclonal IgG bands in the cerebrospinal fluido $f$ portuguese patients with multiple sclerosis: negative results indicate benign disease. Arq Neuropsiquiatr 2005;63:375-379.

20. Fortini AS, Sanders EL, Weinshenker BG, Katzmann JA. Cerebrospinal fluid oligoclonal bands in the diagnosis of multiple sclerosis. Am J Clin Pathol 2003;120:672-675.

21. Fromont A, Couvreur G, Guiguet M, Giroud M, Caudie C, Moreau T. Comparaison de l'immunofixation après électrophorèse sur gel d'agarose avec la focalisation isoélectrique dans la détection des bande oligoclonales d'IgG du liquide céphalo-rachidien de patients atteints de sclérose en plaques. Rev Neurol (Paris) 2005;161:1183-1190.

22. Callander M, Haghighi S, Landtblom AM, et al. Multiple sclerosis immunopathic trait and HLA-DR(2)15 as independent risk factors in multiple sclerosis. Mult Scler 2007;13:441-445.

23. Lau KK, Wong LKS, Li LSW, Chan YW, Li HL, Wong V. Epidemiological study of multiple sclerosis in Hong Kong Chinese: questionnaire survey. HKMJ 2002;8:77-80.

24. Tanaka K, Kujuro Y, Suzuki S, et al. Clinical and laboratory features of in-patients with multiple sclerosis in a University Hospital in Tokyo from 1988-2002. Inter Med 2005;44:560-566.

25. Tintoré M, Rovira A, Rio J, et al. Do oligoclonal bands add information to MRI in fist attacks of multiple sclerosis? Neurology 2008;70:1079-1083.

26. Siritho S, Freedman MS. The prognostic significance of cerebrospinal fluid in multiple sclerosis. J Neurol Sci 2009;279:21-25.

27. Annunziata P, Giorgio A, Santi L, et al. Absence of cerebrospinal fluid oligoclonal bands is associated with delayed disability progression in relapsing-remitting MS patients treated with interferon-B. J Neurol Sci 2006;244:97-102.

28. Bourahoui A, Seze J, Guttierez R, et al. CSF isoelectrofocusing in a large cohort of MS and other neurological diseases. Eur J Neurol 2004;11:525-529.

29. Bednarova J, Stourac P, Adam P. Relevance of immunological variables in neuroborreliosis and multiple sclerosis. Acta Neurol Scand 2005;112: 97-102.

30. Koch M, Heersema D, Moster J, Teelken A, De Keyser J. Cerebrospinal fluid oligoclonal bands and progression of disability in multiple sclerosis. Eur J Neurol 2007;14:797-800.

31. Chang KH, Lyu RK, Chen CM, Hsu WC, Wu YR, Chen ST, Ro LS. Clinical characteristics of multiple sclerosis in Taiwan: a cross-sectional study. Mult Scler 2006;12:501-506. 